\title{
Returns to Facilitating Farmers' Organisations for Distributary Maintenance: Empirical Results from a Pilot Project in Southern Punjab
}

\author{
Mehmood Ul Hassan, Yameen Memon, and Abdul Hamid
}

\begin{abstract}
Institutional reforms currently underway in Pakistan's irrigation and drainage sector require that farmers take over the operation and maintenance responsibilities of their secondary canals. However, the farmers need to be organised first, for which investments are a prerequisite. A great deal of skepticism about the farmers' collective ability and willingness to undertake the needed tasks exists, even now when they are actually organised. This skepticism originates from past experiences when direct subsidies were offered to induce collective action. Theoretically, collective action can be more sustainable if investments are made in capacity building for the tasks that the farmers have to perform to improve the service delivery. Farmers are being organised for distributary operation and maintenance. So far, the delay in formulation of an appropriate legal framework has prevented the irrigation departments from formally transferring the operation and maintenance responsibilities to farmers. Self-help-based maintenance has been the only avenue for farmers to participate in the management of the irrigation system.

The paper uses data pertaining to the cost of facilitation and estimates the amount of resources mobilised for two successive years from a pilot project. The analysis shows that investments made for facilitation do pay off. Investment in facilitation returns 69 percent higher than the actual investment per year during the initial years. In the short-run, the returns to facilitation indicate an increasing trend. The paper argues that when compared to previous approaches adopted in Pakistan, investments for facilitation and capacity building have a greater chance of prompting sustainable collective action for irrigation and drainage management.
\end{abstract}

\section{INTRODUCTION}

Reforms currently underway in Pakistan are intended to restructure the institutional framework for irrigation and drainage services of the large canal system. These reforms aim at withdrawing subsidies by creating autonomous entities at

Mehmood Ul Hassan, Yameen Memon, and Abdul Hamid, respectively, are Senior Social Scientist, Principal Social Scientist and Junior Social Scientist at the International Water Management Institute's (IWMI) Pakistan Programme.

Authors' Note: The authors want to acknowledge with thanks the financial support from the Royal Netherlands Government, IWMI's permission to share the research results, and valuable comments of Dr Ralf Starkloff, IWMI's Management Specialist, as well as those of an anonymous reviewer on earlier versions of this paper. 
various levels of the irrigation and drainage system. The four Provincial Irrigation Departments (PIDs) are being transformed into the Provincial Irrigation and Drainage Authorities (PIDAs). The PIDAs have the mandate to establish financially autonomous Area Water Boards (AWBs) at canal commands, responsible for operation and maintenance (O\&M), as well as for the management of irrigation and drainage facilities located within their areas of jurisdiction. The AWBs will encourage the formation of financially autonomous and self-reliant Farmer Organisations (FOs) on secondary channels to undertake O\&M of their respective distributaries and drainage facilities. Farmers will also pay O\&M costs for the upstream system. The PIDAs, AWBs and FOs are expected to operate as management organisations with sound business principles. Initially, the PIDAs are establishing some pilot AWBs and FOs in all of the four provinces to acquire necessary experience for large-scale replications.

Past approaches to prompt collective action for irrigation system maintenance in Pakistan have been to offer direct subsidies rather than investing in social mobilisation and capacity building of the target group. Such approaches, for example, material incentives for lining the watercourses, however, have met with partial success. Many Water Users Associations could not sustain themselves in the long run and became defunct after successful rehabilitation of the watercourses. This partially can be attributed to lack of investment in human resource development. Such approaches have focussed more on the hardware side than on the software side of collective action. Inducing collective action through incentives of improved capacity for service delivery may prove much more effective.

Several pilot projects underway in three of the four provinces (Punjab, Sindh, and North-West Frontier Province) have organised farmers at the distributary canals. The major focus of the current initiatives of organising farmers is to develop capacity through training and information sharing, rather than providing subsidies on hardware. The expectations from resultant farmer organisations are that these will learn and implement strategies in operation and maintenance of their irrigation and drainage channels that will improve their service delivery. Various government and non-government agencies have facilitated such experiments, which have reached different degrees of maturity. FOs formed through these projects are looking forward to managing their own distributaries, as many of them are currently negotiating the taking over of management responsibilities with the government. The PIDAs express their eagerness to implement the legal framework for the transfer process as soon as it is approved. Once the legal framework comes into effect, the transfer process may gain momentum and PIDAs may focus efforts on forming more FOs.

Farmers need facilitation in terms of information, knowledge, training, and capacity to manage themselves, at least initially, as most of them lack experience with formal organisation. After organising and training farmers the facilitation inputs would eventually be withdrawn because each FO will need to become self-sufficient 
within a stipulated period. If FOs can maintain high O\&M standards as facilitation inputs decline gradually, they may be expected to become sustainable, self-sufficient and self-reliant entities. Likewise, if the FOs learn to undertake more cost-effective O\&M during the subsequent years, these may be able to offer a better service to their members for the money. FOs offering cheaper O\&M may have a better chance of social acceptability and financial sustainability.

The past efforts for strengthening collective action among farmers in Pakistan's irrigation sector could not sustain. Such projects used subsidies as incentives for collective action. Provision of information and training instead of any monetary or physical incentive for strengthening collective action may produce different results.

This paper analyses the case of a pilot FO to address the question of whether facilitation inputs provided to the FOs produce returns in terms of resource mobilisation for the distributary maintenance. The data collected by the field team which organised the FO is analysed to assess the effect of varying levels of facilitation on resource mobilisation and the maintenance work undertaken by the FO.

Section 2 of the paper describes the research locale and the background, as well as the plan and execution of the maintenance activities carried out by the FO. Section 3 discusses the conceptual framework for farmer's organisations in irrigation management and methodology for data analysis. Section 4 presents the results and Section 5, the conclusion.

\section{RESEARCH LOCALE AND BACKGROUND}

The case of the Farmer's Organisation of the Hakra 4-R Distributary, an offtake from the Hakra Branch Canal in the Eastern Sadiqia Canal Command in the southern part of the Punjab Province, serves as the reference. The Hakra 4-R Distributary is a medium- to large-scale secondary canal with an authorised discharge of 5.46 cubic meters per second and a culturable command area of around 18,000 ha. The distributary feeds 124 irrigation outlets through its main channel and two minors. The distributary system's 36-kilometer-long main channel has five dropstructures along its entire length, and serves around 4,700 farms. The farmers comprise a mix of local people, settlers from the time when the irrigation system was constructed during the 1920s and migrants coming from India after the partition of the sub-continent in 1947.

The distributary was in a state of disrepair. Its banks were rapidly deteriorating due to animal and vehicular traffic. The freeboard had almost disappeared. The major maintenance problems of the distributary included bermcutting, widened cross-sections, scouring in the head reach, silt deposition in the tail reach and weak banks, which disturb the water supplies. Unreliable and erratic supplies were causing productivity loss to the farmers. The branch canal's rotational 
schedule, that feeds the distributary, was unorganised [Waheed-uz-Zaman (1998)]. The farmers complained about inequity in water distribution, and wanted improvements to the water supply [Cheema et al. (1997)]. This poor situation with regard to equitable distribution and unreliability of supplies encouraged the farmers to engage in a dialogue among themselves, which was initiated by the field staff of the International Water Management Institute (IWMI). After undergoing a slow, stepwise and carefully planned out process of social organisation for distributary management, the farmers established a farmer organisation to negotiate the takeover of O\&M tasks of the distributary with the PID [Bandaragoda et al. (1997)]. The main organisational strategies revolved around the philosophy of building capacity through investments in training and facilitation. No hardware incentives had been provided to the farmers for inducing collective action.

The FO is a three-tiered organisation representing farmers at the watercourse, subsystem and the distributary level. The social organisation process relied heavily on information provision, local capacity building through training, bringing farmers together through evolving consensus. No physical or monetary incentive has been given to the farmers for engaging them in the collective action.

IWMI collaborated with the FO to assess the overall maintenance requirements of the distributary with active participation by farmers and their leaders [Waheed-uz-Zaman (1998)]. The farmer-leaders have been trained in carrying out simple water measurements, as well as in carrying out financial and organisational tasks. Currently, the FO and the government are at the negotiating table to finalise the transfer of O\&M responsibilities at the distributary canal. The farmers intend to improve the physical condition of the distributary through undertaking maintenance and repairs. They want to distribute water equitably among the members. The FO is willing to pay a proportionate share of the main system's O\&M expenditures.

Apart from verbal commitments indicating farmers' willingness to pay for O\&M, the FO has demonstrated its capacity for collective action by undertaking selfhelp maintenance activities during the 1997-98 and 1998-99 canal closure periods. These activities have been documented by the project staff [Waheed-uz-Zaman (1998a)]. The levels of support from IWMI as well as the resources mobilised varied for these two years.

The FO general body met in December 1997, and members decided to demonstrate their collective willingness and ability to participate in the performance of O\&M responsibilities. The FO interacted with the local staff of the Punjab Irrigation Department (PID) to plan and coordinate the maintenance activities. The PID informed that the two minors and the tail reach of the distributary were being lined, and needed no maintenance. The middle reach of the main channel did not have much maintenance problems. Therefore, the FO decided to strengthen the banks of the distributary in the head reach as, in the past, most breeches occurred in this reach due to weak banks. The FO formed a maintenance committee comprising 5 
farmers-members. The committee with assistance from the facilitators inspected the potential sites and identified areas requiring maintenance. The maintenance committee decided to undertake maintenance for five consecutive days. By dividing the head reach into five sub-reaches, one sub-reach was allocated to each of the 5 subsystem level organisations. Each subsystem organisation performed maintenance tasks for one of the five days. The committee also evaluated the work performance of various maintenance groups. The team of social organisers facilitated the process of information dissemination, organisation and supervision. The irrigation staff was requested to participate in the activity for guiding the FO. However, the staff did not show up due to their tight duties elsewhere as well as due to their negative feelings about farmer's participation.

During the 1998-99 canal closure the FO was informed that the maintenance work was assigned to a contractor, who would strengthen the banks of the distributary after a few months, and that the FO's maintenance initiatives would not be required. However, the FO decided to undertake maintenance for demonstrating their willingness as well as to safeguard against the immediate breeches after the closure. Again, a maintenance committee was appointed and assistance from the PID was sought, which deputed the sub-engineer to participate in the planning and execution of the activities. All the farmers from various subsystem organisations had to undertake maintenance activities on the same day. The maintenance committee identified ten most weak sites. The committee assigned these sights to various maintenance groups comprising 5-15 farmers and appointed one farmer-leader to supervise the work. The maintenance groups were organised proportionate to the number of tractors and manpower, and depending on the nature of the work to be performed. Each maintenance group was also accompanied by one of several PID maintenance staff members.

Under the prevailing legal framework, the PID reserves all the rights for distributary O\&M, and the distributary channel's maintenance was not the FO's responsibility. Therefore, the FO only wanted to demonstrate its collective willingness and ability to manage the distributary O\&M. Since the FO's maintenance initiatives were not directed towards carrying out the necessary repairs, resource mobilisation may not have necessarily resulted in quality work.

\section{CONCEPTUAL FRAMEWORK AND METHODOLOGY}

During the colonial rule, British engineers constructed Pakistan's huge canal irrigation system up to 1930 s and the users were settled gradually as the system evolved. Since then, the farmers have always been seen as beneficiaries of the system without any right to influence management at the higher levels. Poor management of the irrigation system has resulted into unsatisfactory service to farmers. That is also one of the reasons for stagnant productivity of major crops, as well as waterlogging and salinity due to unreliable and inequitable supplies. Some 
researchers [for instance, Meinzen-Dick et al. (1995)] believe that the farmers are less likely to pay fees to cover full O\&M costs if they are excluded at the time of system planning and construction. This argument seems valid for Pakistan's canal system, which is now facing severe financial crises, as the assessed water rates are not collected. In general, user participation in the O\&M increases the likelihood for systems' better maintenance [World Bank (1993), p. 55].

Owing to the growing burden of subsidised irrigation, governments generally tend to involve users at various stages of planning, construction and O\&M of irrigation system with the intention of reducing government's expenditure [Byrnes (1992), p. 52]. Investments in irrigation institutions, such as water users' associations, may lead to a positive rate of return from participatory projects [Bagadion and Korten (1991)]. Like governments, participatory projects do have additional costs for farmers, such as increased contributions in cash and kind for O\&M, transaction costs that include convening and attending meetings, taking over management functions, conflict management etc. However, if the farmers themselves are able to set the level of contributions and control their use, it is more likely that they would pay higher contributions than they pay under government control.

Generally, the farmers will respond positively to an irrigation system that gives them a certain degree of control over water supplies. Once the farmers take over the responsibility for managing the system, their confidence in their management capacities will grow with the passage of time. The farmers should have enough degree of control and authority that allows them to perform their tasks at a reasonable cost [Meinzen-Dick et al. (1995)]. Farmers' involvement gives them a 'sense of ownership' and they tend to protect irrigation facilities [NIACONSULT (1993); Merry and Murray-Rust (1991)]. Farmers may be willing to bear additional costs if they see a return to their investments in terms of improved irrigation service [Meinzen-Dick et al. (1995)], as they get rapid responses to system breakdowns [Plusquellec (1994)]. However, organising them into irrigation associations may require a great deal of persuasion and facilitation. As agriculturists, farmers' livelihoods also depend on a number of non-water inputs, and their organisations may assume other responsibilities as they become well organised and trained for irrigation management [Meinzen-Dick et al. (1995), p. 7].

The farmers should decide how they desire to carry out activities by themselves. The catalyst or the organisers should only facilitate the process and refrain from imposing their agenda [Korten (1993), p. 2; Cernea and Meinzen-Dick (1992)]. The farmer organisations should clearly specify rules that allocate responsibilities, conflict management, resource mobilisation and management [Ostrom (1992); Tang (1992)]. Facilitators should act as farmers' communication channels until higher level organisations are formed and can assume the role, or until the farmers are sufficiently familiar with the system to accomplish this on their own. In effect, the organisers should act as low-tech interactive communication media, by 
broadcasting a series of focused messages to individual farmers and groups [Meinzen-Dick et al. (1995)]. Technical training and supervision should be provided to the organisation and its leadership until the organisation devolves the capacity to carry out tasks of its own.

Though an enabling law is already in place in the context of the institutional reforms in Pakistan, proceeding further with turning the responsibilities over to the FOs for distributary management is limited in several respects [Muhammad (1998)]. While these projects were planned, the assumption was that the government would be ready with all essential institutional mechanisms to transfer the responsibilities to the FOs as soon as these were organised [See, for instance, IIMI (1996)]. However, no handing over of responsibilities has taken place to date. The FOs, together with the project staff, are waiting for the responsibilities to be transferred from the government to the FOs, which necessitates continued facilitation until the FOs acquire responsibilities.

The situation of organised farmers waiting for responsibilities has an inherent risk of FOs becoming more dependant on continued facilitation, because with the passage of time, the farmers may lose their initial momentum and interest. A situation like this would be counter-productive to the central idea of the institutional reforms and may lead to greater subsidy in terms of increased costs of these projects. Institutional reforms will only be relevant to improve the performance of the irrigation system if these FOs prove to be sustainable with the passage of time. Even if these organisations continue to require a certain degree of facilitation and catalysing efforts, the cost of the facilitation has to be less than the benefits arising from these organisations for the reforms to be meaningful in terms of cost savings to the government.

Since formal responsibilities have not been assigned to the FOs as yet, the only possibility of assessing the outcome of facilitating FOs is to assess the self-help maintenance activities. The FO of the Hakra 4-R Distributary has been carrying out maintenance for two consecutive years. The explicit objective of the maintenance activities was to demonstrate collective willingness and ability to take over O\&M of the distributary, yet some physical work was also accomplished. The objective of demonstrating willingness and ability behind organising maintenance may have adversely affected the potential amount of work that the FO could have accomplished with the same set of mobilised resources, as it would tend to use resources more efficiently. Yet, the FO's undertaking of some of the maintenance activities have saved the government some funds for other investments. The government therefore, has definitely benefited from these maintenance activities. On the other hand, if the amount of work done was higher than the amount of resource cost, farmers would also have benefited, because the canal could have served them better after the maintenance. 
Conceptually, the degree of resources mobilised by the farmers for maintenance would depend on the level and extent of facilitation by the project staff. More concerted efforts would lead to more resource mobilisation, and vice versa. Likewise, the extent of the maintenance work performed would depend on the level of resources mobilised for various maintenance activities. If the work performed per unit of resources improves overtime, the implication will be that the resource use productivity between different years has increased, and that the FO has learned how to use resources more efficiently. Thus, three variables could be used in our analysis, i.e., facilitation inputs from the project staff, resources mobilised for maintenance, and the maintenance work performed. All of these three variables can be translated in monetary terms for a given year, $t$, and more specifically, be identified as the cost of facilitation $\left(F_{t}\right)$, the value of resources mobilised $\left(R_{t}\right)$, and the value of the work done $\left(W_{t}\right)$.

The ratio of the value of resources mobilised to facilitation costs for the year $t$ $\left(R_{t} / F_{t}\right)$ represents returns to facilitation $\left(R F_{t}\right)$. Likewise, the ratio of the value of the work accomplished to the value of resources mobilised in the year $t\left(W_{t} / R_{t}\right)$ represents returns to resource mobilisation $\left(R R_{t}\right)$. Similarly, the ratio of value of work done in the year $t$ to the cost of facilitation in the year $t\left(W_{t} / F_{t}\right)$ represents the work response to facilitation $\left(W F_{t}\right)$. Since data for only two years are available, the conclusions drawn indicate a short-term trend.

In this paper, we test the hypothesis that the returns to facilitation increase during the successive years, or, $R F_{2}>R F_{1}$, implying that the FO can mobilise more resources per unit of facilitation. An important limitation of this analysis, however, is that the work done by the FO was not evaluated technically. This precluded the possibility of evaluating the work response to the resource mobilisation.

Both, the project staff and the farmer-leaders participated in the mobilisation efforts. The farmer-leaders' inputs used during the mobilisation effort are not valued as facilitation, as these reflect FOs capacity to undertake maintenance, and are treated as resources mobilised.

\section{Data Requirements and Acquisition}

Testing the hypothesis outlined above requires data pertaining to the costs of facilitation and the value of the resources mobilised. IWMI's project staff recorded the maintenance activities as a part of their routine process documentation. This data provided the information relating to the value of resources mobilised, such as number of farmers, tractors, fuel consumption, distance travelled and the time spent at work. IWMI's records provided information about the cost of facilitation such as salaries of staff, fuel and maintenance costs of the vehicles etc.

\section{Cost of Facilitation}

The cost of facilitation includes staff salaries, benefits, and transport. The cost for individual staff members have been calculated by multiplying their daily salaries 
and benefits by the number of days each staff member was involved in the activity. The field staff uses motorbikes to travel in the field. The total fuel consumption and the depreciation and maintenance costs have been incorporated for the use of motorbikes. For other vehicles, the distance travelled during the activity has been multiplied by the per kilometre rates for fuels, maintenance and depreciation. The cost for the driver's labour has also been included.

\section{Value of Resources Mobilised}

Manpower and tractors were mobilised to undertake the maintenance activities. The manpower used spades and undertook activities, such as filling rain cuts etc., which did not require machinery. Tractors were used for earthmoving, strengthening of banks and removing silt from the channel bed. The time farmerleaders spend on surveying the distributary, assessing the maintenance, identifying sites as well as motivating their farmer-colleagues is treated as a resource mobilised. Leaders' rates have been assessed at double the wage rate of that for ordinary farmers, whereas market wage rates have been used for ordinary farmers, because leaders time has been considered to be more valuable.

Tractors had two important cost elements, i.e., for bringing and sending back the tractor to the work site and the cost of the work performed. The former considers the total distance for travelling from the origin to the work destination and back. The total amount of fuel used has been determined and multiplied by the fuel price to obtain the cost of the fuel consumed. Generally, tractors are hired out at a standard rate per hour. This rate has been multiplied by the total number of hours that tractors worked at the sites. While no refreshments were served during 1997-98 as the maintenance was undertaken during the month of Ramadhan, the cost of refreshments to the workers in 1998-99 was borne by the FO, and has been treated as a resource mobilised.

\section{RESULTS}

The summarised form of cost calculations for facilitation and the value of resources mobilised (Annexes 2 and 3) indicates that 65 man-days were used for facilitation during 1997-98 which was reduced to 22 man-days during the subsequent year. The costs of facilitators to reach farmers and their leaders were also included, which also declined during 1998-99. Compared to 1997-98, the cost of facilitation in 1998-99 was cut down by 33 percent at current prices and by almost half at the prices of 1997-98.

The value of resources mobilised during the second year also declined as a result of lower facilitation inputs. At 1997-98 prices, the decline in the value of manpower mobilised in 1998-99 is over one-fifth, and equivalent to around 14 percent at current prices. Likewise, the value of the machinery mobilised during 1998-99 was almost 40 percent less than that during 1997-98. Overall, the decline in 
the total value of resources mobilised equalled around one-third that of the value for 1997-98. Thus, a direct, but not necessarily proportionate relationship between the facilitation inputs and the value of resources mobilised, becomes evident.

Table 1 shows the changes in facilitation inputs and resources mobilised. While the facilitation inputs during 1998-99 were almost half that of the previous year, the decline in the value of resources mobilised was one-third. The decline in resource mobilisation might not be due to decreased facilitation alone. Other factors such as unimproved water supply situation after the last years' activities, especially in the tail areas, would also have curtailed farmer's inputs. Besides, the disturbance in the water supply due to initiation of work on distributary lining, which made the supply erratic, could be another reason for lesser resource mobilisation. Another possible reason for less resource mobilisation during 1998-99 could be allocation of money by PID for bank strengthening. The farmers were afraid that their efforts would not save money to the government, as the farmers would undertake work and the irrigation department would claim false bills against those works. If part of the reduced resource mobilisation during 1998-99 is attributed to above mentioned factors, more returns to facilitation could be expected.

Table 1

Changes in Returns Over Time to Facilitation at the Hakra 4-R Distributary

\begin{tabular}{lrrrrr}
\hline Description & $1997-98$ & $1998-99$ & Change & $1998-99^{*}$ & Change $^{*}$ \\
\hline$F_{t}$ (Rupees) & 85,823 & 55,805 & $-35 \%$ & 45,078 & $-47 \%$ \\
$R_{t}$ (Rupees) & 114,440 & 81,955 & $-28 \%$ & 76,255 & $-33 \%$ \\
$R F_{t}$ & 1.33 & 1.48 & $+11 \%$ & 1.69 & $+27 \%$ \\
\hline
\end{tabular}

${ }^{*}$ at $1997-98$ prices.

In terms of returns to facilitation, each rupee invested on facilitation in 199798 yielded 1.33 rupees, which increased at current prices to 1.48 rupees during the following year. The returns in 1998-99 in real terms were even higher, to the tune of 1.69 rupee per rupee of facilitation. The returns in real terms have increased by 27 percent when compared to the base year, which shows that gradually withdrawing facilitation might be possible without much impact on resource mobilisation. If the FO keeps this momentum, it may become possible to sustain collective maintenance with minimum facilitation. To withdraw facilitation completely, however, would require more efforts. Facilitation would be required to build the FO's capacity to undertake various managerial and other tasks, which will enable the FO to mobilise resources and undertake maintenance more efficiently. Such facilitation may include devising mechanisms to assess maintenance needs through "walk-thru" surveys, ${ }^{1}$ prioritising and planning the maintenance.

${ }^{1}$ The term "Walk-thru" surveys is used by engineers to travel on a channel together with farmers and engineers to inspect the physical defects in the channel, and noting down the type of the damage and possible causes. 
To assess the value of the work done, the maintenance requirements need to be assessed technically in terms of materials and manpower. Likewise, after the work is completed, technical procedures have to be employed to calculate the value of work. In general, however, the PID staff feels experienced enough to judge the quantity and quality of work without involving precise measurements. The staff makes inspections and observations to evaluate and value the work performance. The Haroonabad Sub-division Irrigation Department's Sub-divisional Officer (SDO) judged a saving of 0.3 to 0.4 million rupees as a result of farmers' maintenance initiatives in 1997-98 [Vander Velde (1998), p. 13]. If this estimate is considered valid, then the FO had performed the work at almost one-third of the cost that the PID would incur. Since the FO has established that it can undertake the maintenance works at one-third of the cost incurred by PID, any investment on facilitation which keeps the cost of work within PID estimates would still save some funds, and would be cost effective.

The reason of PID's being expensive is that they undertake maintenance through contractual system. The contract system has its own limitations, such as corruption on award of contract, compromise on quality of work etc. Besides, the contractor has also to earn some profit out of the contract. Thus, the contract system is expensive compared to farmer's direct undertaking of works. The FOs can potentially reduce transaction costs of the contractual system.

\section{CONCLUSIONS AND POLICY IMPLICATIONS}

Canal irrigation in the Bahwalnagar District of the Punjab Province is the only source of irrigation owing to unsuitable groundwater. Canal supplies have been rather erratic and inequitable for various sets of users for many years, causing productivity losses for many water users. Erratic water supplies explain farmers' willingness to operate and maintain their irrigation channels themselves. Though the farmers pay water charges for the O\&M of the system, the amounts still fall short of the requirements. The government's desire to eliminate subsidies on water requires that the farmers take over the management of distributary channels. The foregoing analysis suggests that the FO of the Hakra 4-R Distributary has shown its collective willingness and ability to handle the maintenance of the distributary of its own even without incentives. It is important to note that the extent of resource mobilisation depends on the level of motivation of the farmers and their perceptions about the benefits arising out of the maintenance. Since the maintenance initiatives by the FO were totally voluntary, many farmers who would have otherwise contributed, may not have contributed because the FO did not have any sanctioning power for nonparticipants. The full potential for resource mobilisation therefore may not have been exploited, which would increase as the FO is given full responsibility for canal operation and maintenance together with required authority and power. Thus, 
appropriateness of the legal and administrative instruments empowering the FO is extremely important.

Theoretically, organised farmers have a comparative advantage over the government's management for the O\&M of the irrigation and drainage systems, which seems to be applicable for the distributary being referred to. The judgement by the irrigation staff, that the FO accomplished maintenance at one third of the cost of the PID, indicates that organised farmers can mobilise resources to undertake work at a lower cost than that incurred by the PID. At the collective level, farmers seem to display more interest in the physical upkeep of their channel than does the irrigation bureaucracy. Being physically close to the system and direct beneficiaries of improved condition of the distributary, it is much easier for farmers to arrange needed inputs, and at a cheaper cost.

This paper shows that the farmers may become strong if they receive the required facilitation in the earlier years of organisation. However, the projects organising farmers must chalk out a 'weaning strategy' right from the start. Gradual reduction in facilitation helps to induce sustainability in the organisation, as the organised farmers may gradually take over the needed tasks themselves. Certain services, such as assessing maintenance needs, designing of new infrastructure components for improved water delivery, advice on improving water charge assessment and collection, improving accounting, etc. may yet be needed from outside, for which mechanisms have to be devised.

However, the effectiveness of farmers' efforts in O\&M would depend on the degree of improvement in the quality of irrigation service they receive after making resources available for the O\&M of the distributary. A lack of clear benefits arising out of maintenance may adversely impact farmers' enthusiasm to operate and manage their irrigation or drainage system. It is imperative that the PIDAs should devolve the O\&M responsibilities as early as possible to those FOs that show the willingness to undertake needed functions. Indeed, farmers' willingness also depends on the way they have been motivated and assisted to form their organisations. Thus, the appropriateness of organisational methodologies to foster collective action is most important for the success of the institutional reforms being implemented in the irrigation and drainage sector.

Looking at Pakistan's past history of collective action, where policy level incentives-such as low interest loans for cooperatives or cheap watercourse improvements - have not been a sustainable option, the experience of the Hakra 4-R Distributary FO offers an opportunity to use capacity building and training as an incentive for sustainable collective action for water resource management. 
Annexures

Annexure 1

Cost on Facilitating the Farmers' Organisation for Maintenance at the Hakra 4-R Distributary during the Two Canal Closure Periods

\begin{tabular}{|c|c|c|c|c|c|c|c|c|}
\hline \multirow[b]{2}{*}{ Cost Item (Units) } & \multicolumn{3}{|c|}{ 1997-98 } & \multicolumn{3}{|c|}{ 1998-99 } & \multicolumn{2}{|c|}{$\begin{array}{c}1998-99 \text { at } 1997-98 \\
\text { Prices }\end{array}$} \\
\hline & $\begin{array}{l}\text { Units } \\
\text { Used }\end{array}$ & $\begin{array}{c}\text { Average } \\
\text { Unit Cost } \\
\text { (Rs) }\end{array}$ & $\begin{array}{l}\text { Total Cost } \\
\text { (Rs) }\end{array}$ & Units & $\begin{array}{l}\text { Unit Cost } \\
\text { (Rs) }\end{array}$ & $\begin{array}{l}\text { Total } \\
\text { Cost } \\
\text { (Rs) } \\
\end{array}$ & $\begin{array}{l}\text { Unit Cost } \\
\text { (Rs) }\end{array}$ & $\begin{array}{l}\text { Total Cost } \\
\text { (Rs) }\end{array}$ \\
\hline (A) Salary and Benefits of Staff (Mandays) & 65 & 463.1 & 30,101 & 22 & 778.1 & 17,118 & 463.1 & 10,188 \\
\hline (B) Mobility Cost & & & 55,722 & & & 38,687 & & 34,890 \\
\hline Motorbike (Kms.) & 22,759 & 1.5 & 34,139 & 12,638 & 1.7 & 21,485 & 1.5 & 18,957 \\
\hline Vehicles (Kms.) & 1,910 & 11.3 & 21,583 & 1,410 & 12.2 & 17,202 & 11.3 & 15,933 \\
\hline Total Cost (Rupees) & & & 85,823 & & & 55,205 & & 45,078 \\
\hline
\end{tabular}


Annexure 2

Value of Resources Mobilised for Maintenance at the Hakra 4-R Distributary during the Two Canal Closure Periods

\begin{tabular}{|c|c|c|c|c|c|c|c|c|}
\hline \multirow[b]{2}{*}{ Item (Units) } & \multicolumn{3}{|c|}{ 1997-98 } & \multicolumn{3}{|c|}{ 1998-99 } & \multicolumn{2}{|c|}{$\begin{array}{c}1998-99 \text { at } 1997-98 \\
\text { Prices }\end{array}$} \\
\hline & Units & $\begin{array}{l}\text { Unit Value } \\
\text { (Rs) }\end{array}$ & $\begin{array}{c}\text { Total } \\
\text { Value } \\
\text { (Rs) }\end{array}$ & Units & $\begin{array}{c}\text { Unit } \\
\text { Value (Rs) }\end{array}$ & $\begin{array}{c}\text { Total } \\
\text { Value } \\
\text { (Rs) }\end{array}$ & $\begin{array}{l}\text { Unit Value } \\
\text { (Rs) }\end{array}$ & $\begin{array}{c}\text { Total } \\
\text { Value } \\
\text { (Rs) }\end{array}$ \\
\hline (A) Manpower (Mandays) & & & 72,700 & & & 62,700 & & 57,000 \\
\hline Farmers & 674 & 100 & 67,400 & 540 & 110 & 59,400 & 100 & 54,000 \\
\hline Farmer-leaders & 26.5 & 200 & 5,300 & 15 & 220 & 3,300 & 200 & 3,000 \\
\hline (B) Machinery with Operators & & & 41,740 & & & 16,390 & & 16,390 \\
\hline (C) Refreshments & & & $\mathbf{0}$ & & & 2,865 & & 2,865 \\
\hline Total Value (Rupees) & & & 114,440 & & & 81,955 & & 76,255 \\
\hline
\end{tabular}




\section{REFERENCES}

Bagadion, B. U., and F. F. Korten (1991) Developing Irrigator's Organisations: A Learning Process Approach. In M. M. Cernea (ed.) Putting People First: Sociological Variables in Rural Development. (Second Edition) U. K.: Oxford University Press.

Bandaragoda, D. J., M. U. Hassan, Z. I. Mirza, M. A. Cheema, and Waheed-uzZaman (1997) Organising Water Users for Distributary Management: Preliminary Results from a Pilot Study in the Hakra 4-R Distributary of the Eastern Sadiqia Canal System of Pakistan's Punjab Province. Pakistan National Programme. International Irrigation Management Institute, Lahore. April. (Research Report No. R-25.)

Byrnes, K. J. (1992) Water Users Associations in World Bank-Assisted Projects in Pakistan. World Bank, Washington, D. C. (World Bank Technical Paper No. 173.)

Cernea, M. M., and R. Meinzen-Dick (1992) Design for Water Users Associations: Organisational Characteristics in Developing and Improving Irrigation and Drainage Systems. World Bank, Washington, D. C. (World Bank Technical Paper No. 178.)

Cheema, M. A., Z. I. Mirza, M. U. Hassan, and D. J. Bandaragoda (1997) SocioEconomic Baseline Survey for a Pilot Project on Water Users Organisations in the Hakra 4-R Distributary Command Area, Punjab. Pakistan National Programme. International Irrigation Management Institute, Lahore. December. (Research Report No. R-37.)

International Irrigation Management Institute (IIMI) Pakistan (1996) Managing Irrigation for Environmentally Sustainable Agriculture in Pakistan: Plan of Operations. Pakistan National Programme. International Irrigation Management Institute, Lahore. September, 1998.

Korten, F. F. (1991) The Policy Framework for Community Management. In D. C. Korten (ed.) Community Management: Asian Experience and Perspective. West Harford. CT: Kumarian Press.

Meinzen-Dick, R., R. Reidinger, and A. Manzardo (1995) Participation in Irrigation. Environment Department, World Bank, Washington, D. C. (Participation Series, Paper No. 003.)

Merry, D. J., and D. H. Murray-Rust (1991) Peoples Participation in the Gai Oya Rehabilitation Project as Viewed by Agency Personnel in Farmers in the Management of Irrigation Systems. New Delhi: Sterling Publishers Private Limited.

Muhammad, Dil (1998) Legal Framework for Irrigation Management in Punjab and Sindh Provinces of Pakistan. Pakistan National Programme. International Irrigation Management Institute, Lahore. September. (Consultancy Report No. C-11.) 
NIACONSULT Inc. (1993) An Evaluation of the Impact of the Farmer's Participation on the National Irrigation Systems' Performance. NIACONSULT Inc., Philippines. (Final Report.)

Plusquellec, H. (1994) India, Morocco, Pakistan: Mission Report on Water Users Associations. World Bank, Washington, D. C.

Tang, S. Y. (1992) Institutions and Collective Action: Self-governance in Irrigation. San Francisco: Institute of Contemporary Studies.

Vander Velde, E. J. (1998) Progress in Participatory Irrigation Management in Pakistan: A Report on Pilot Projects in Farmer Organisation at the Secondary Canal Level. Asian Development Bank, Manila, Philippines. (Draft Report.)

Waheed-uz-Zaman (1998) Application of Operation and Maintenance Activities to Support of Participatory Irrigation Management. Center of Excellence in Water Resource Engineering, University of Engineering and Technology, Lahore. (M. Phil. Thesis.)

Waheed-uz-Zaman (1998a) Self-help Maintenance Activities by the Water Users Federation of Hakra 4-R Distributary. Pakistan National Programme. International Irrigation Management Institute, Lahore. February. (Research Report No. R-44.)

World Bank (1993) Water Resource Management: A World Bank Policy Paper. World Bank, Washington, D. C. 